BULLETIN Bulletin hispanique

HISPANIQUE Université Michel de Montaigne Bordeaux

$112-2 \mid 2010$

Varia

\title{
La problemática de adivas (Libro de Buen Amor, 302c)
}

José Jurado

\section{(2) OpenEdition}

\section{Journals}

Edición electrónica

URL: http://journals.openedition.org/bulletinhispanique/1262

DOI: 10.4000/bulletinhispanique.1262

ISSN: 1775-3821

Editor

Presses universitaires de Bordeaux

Edición impresa

Fecha de publicación: 31 diciembre 2010

Paginación: 763-773

ISBN: 978-2-86781-709-0

ISSN: 0007-4640

Referencia electrónica

José Jurado, « La problemática de adivas (Libro de Buen Amor, 302c) », Bulletin hispanique [En línea],

112-2 | 2010, Publicado el 05 enero 2014, consultado el 20 abril 2019. URL : http://

journals.openedition.org/bulletinhispanique/1262 ; DOI : 10.4000/bulletinhispanique.1262

Tous droits réservés 


\title{
La problemática de adivas (Libro de Buen Amor, 302c)
}

\author{
José JuRAdo \\ Carleton University
}

Commentaire sur les diverses acceptions du mot adiva y compris celle non enregistrée jusqu'à aujourd'hui dans les traités lexicologiques où l'on précise aussi de manière argumentée le sens concret de ce substantif dans le contexte narratif du Libro de Buen Amor.

Coméntanse las diversas acepciones que tiene el vocablo adiva, incluida la no registrada hasta el presente en los tratados lexicológicos y se precisa argumentalmente la noción con que se toma el dicho sustantivo en el contexto narrativo del Libro de Buen Amor.

A commentary on the different meanings of the word adiva, including one not yet registered in lexicological treatises; also specifies with appropriate arguments the meaning this word takes on in the narrative context of the Libro de Buen Amor.

Mots-clés : adivaladiblaldibladife - adivas - Libro de buen amor - Lexicologie Traités vétérinaires - Parotidite - Chacal.

El cavallo, con el miedo, fuyó a aguas bivas, avia mucho comido de yervas muy esquivas, iva mucho cansado: tomáronlo adivas.

Ansí mueren los locos golosos do tú ý vas.

$\mathrm{E}$ L Arcipreste-poeta, para ilustrar las malas consecuencias del vicio de la gula («muerte muy rebatada trae la golossina / al cuerpo muy goloso e al alma mesquina» 297ab), aporta una fábula con lo sucedido a dos Bulletin Hispanique, Tome 112, nº 2 - décembre 2010 - p. 763 à 773. 
inmoderados glotones, un león y un caballo: el primero fue matado a coces por el caballo, su vasallo, al haberlo querido devorar, echóle frío, muerto; del otro, envenenado por haber engullido muchas malas hierbas, se dice, tomáronlo adivas.

Adivas, en la estrofa expresada arriba, lo entendió J. Cejador (1913) en el sentido de «enfermedad como la esquinancia en los hombres, que es inflamación de garganta [en las caballerías]»; interpretación que desplazó la del primer editor del poema ruiciano, y la que se ha venido aceptando como lo adecuado al texto por los editores subsiguientes que comentan el locus ruiciano: M. Brey (1954), G. Chiarini (1964), J. Fontanels - L. Pons (1971), N. Salvador (1972), P. Jauralde (1981), A. Blecua (1983, 1992), J. Meléndez (1985), etc. J. Corominas deja sin aclarar qué sea adivas en su edición del LBA (1967); pero en los estudios que en su inapreciable diccionario dedica a adivas el año de 1955 ("cierta inflamación de la garganta en las bestias») y a adiveladiva («variedad de chacal») se contradice, creando confusión, puesto que fundamenta la distinta significación de uno y otro vocablo acudiendo a Juan Ruiz, esto es, al v. 302a de su poema ${ }^{1}$.

Valga comenzar el presente apuntamiento seńalando un distingo $-\mathrm{y}$ precisión- fundamental al término veterinario adivas indicado por los editores del $L B A$. Tal adivas (vocablo diferente del que trataremos adelante) es, desde luego, enfermedad caballar: una dolencia que afecta a la garganta. El primer escritor que la define es, según creo, Antonio de Nebrija («adivas de bestia: anginas", y en el artículo siguiente indica su nombre griego: ouvór $\chi \eta)^{2}$. Repite la idea, con nuevo detalle, Covarrubias («cierta enfermedad que da a las bestias en la garganta que las ahoga -equivalente a las anginas en el hombre-») $)^{3}$. Tal caracterización veterinaria es la única que recogen los tratados de albeitería de antaño ${ }^{4}$, y la que pasa a los diccionarios de la Real Academia y a las obras lexicológicas modernas. Sin cuestionar, pues, esta acepción de adivas, es importante señalar que el vocablo posee otro distinto significado de maladía (valga el arcaísmo) o dolencia también propia de bestias, a saber: 'tumor superficial, quiste, lupia, lobado o car-

1. DCE, I: 39b y 40a respectivamente. Corominas no modifica estas ideas en su última edición del Diccionario (Madrid, Gredos, 1980-1991, 6 vols.), trabajada con la colaboración de José A. Pascual, t. I, p. 56a.

2. Antonio de Nebrija, Vocabulario Español-Latino, ed. R. Acad. Española, Madrid, 1951, s. v.; facsimilar de la obra original, cuyo título es Dictionarium ex hispaniensi in latinum sermonem, Salamanca, ¿1495?.

3. Sebastián de Covarrubias, Tesoro de la lengua castellana o española, Madrid, 1611; ed. de Barcelona, 1943, s. v.

4. Por ejemplo, el Discurso de Albeytería... de Francisco B. Ramírez (Madrid, 1629); las Instituciones de Albeytería de Francisco García Cabero (Madrid, 1730-48, 2 vols.), etc. 
nosidad infecta que crece bajo la piel del cuello, o en la de los encuentros, de los cuadrúpedos mayores. Importante, $1^{\circ}$, porque -salvo error- ningún diccionario lingüístico ni obras del tipo antedicho recogen o mencionan esta 'nueva' significación mórbica del vocablo, y $2^{\circ}$, en particular, porque la única docencia medieval que de la voz se conoce, referida a enfermedad de bestia, lleva concretamente la nueva noción que apuntamos, no la de 'mal de garganta'.

He aquí el texto aludido, constante en el Libro de los caballos, obra anónima de hacia el tercer cuarto del s. XIII:

Título LI. Dela enfermedat que dizen adiuas. Faze se a los cauallos una malantia quel dizen algunos omnes adiuas, e faze se de sobre habundancia de sangre. Et ay algunos omnes que catan esta dolençia en el cuello o se aiunta la cabeça ${ }^{5}$, assi quel fienden el cuero con un cuchillo e escaruan de con la puncta e a sazones sacan le dende unas landres que se fazen a todos los cauallos, hy esto es cosa de grand periglo, e non de guareçimiento, saluo ventura. Ay otros que los sangran en las narizes e en la cola. Esto es mejor mas non es guaresçimiento del todo, que la sobre abundançia dela sangre non pued escorrecha mientre guareçer si non por sus sangrias naturales, porque non sele torne la malentia a menudo. Ende conuiene pora guareçer esta dolençia que no se torne al cauallo a menudo a sangrar le en la uena capital que descende por medio al cuerpo e sacalle pieça de sangre, e dende a IX dias sangrar le en esta misma uena otra uez, e sacarle dos libras de sangre, e seet çierto que non podra auer esta dolençia enel por dos annos o mas. E ay otros quel sangran en la uena que es de iuso el baço de somo e en la uena gorda que es so la lengua, e estas son sangrias que conuiene[n] a esta dolencia ${ }^{6}$.

El DHLE indebidamente aporta este pasaje en apoyo del concepto 'inflamación de las parótides del bruto': recoge de él sólo sus dos primeros renglones (esto es: «Et ay algunos omnes que catan esta dolençia... estas son sangrías que conuiene[n] a esta dolençia» ${ }^{7}$ ), omitiendo del texto medieval aquí reproducido los párrafos que explícitamente caracterizan a la dolencia que se describe, distinta obviamente de la inflamación antedicha.

Las docencias de adivas relativas a uno u otro morbo bestial en textos literarios del pasado son escasas y aun algunas de ellas un tanto confusas o

5. O se aiunta la cabeça: entiéndase 'donde se une la cabeza', 'en la coyuntura de la cabeza' ( $O$ es adverbio).

6. El libro de caballos, edición de Georg Sachs, Madrid, 1936, p. 29-30.

7. DHLE, t. I, p. 726b. 
imprecisas ${ }^{8}$. Valgan unos ejemplos. El primero, tomado de la Farsa Salmantina, viene puesto en boca del pastor Beltrán que incita al temeroso y remolón Estudiante a entrar en casa de la moza Teresa a tomar colación:

.... $\mathrm{a}$ e, ¿¿dices que no puedes?

¿qués aquesto?, ¿no estás bueno?

¡O dolor!

y ¡qué aueys auido, amor!

Las orejas teneys frias

¡Ay Jesu Christo, Señor,

si son algunas adiuas

que aueys...?

Versos finales imprecisos; tal vez haya que entender que Palau, escritor de mediados del s. XVI -en boca del pastor-se está refiriendo, en su suposición con los tales dos versos, no a un posible mal de garganta como quiere el DHLE, sino a un imaginado tumor lupiano localizado próximo a la oreja; nótese al respecto el locativo sintagma o se aiunta la cabeça del citado pasaje del libro de los caballos.

Con la misma dirección intencional hacia la dicha afección de piel suponemos hay que interpretar el siguiente pasaje dialogado de La Lozana andaluza, en razón al repetido juego con el vocablo pellejo (desatiéndase su doble sentido obsceno), que es, sin duda, lo que lleva a Lozana a traer, a su memoria y a su boca el adivas textual, además, claro está, de la rima prosáica de pellejón... cosón. Ulixes ha llamado a la puerta:

Valerián. ¿Qué se hace, señora?.

Lozana (responde). 'Señores, cerner y amasar y ordenar de pellejar'.

Ulixes. $\quad$ Eso de 'pellejar', que me plaze: pellejedes, pellejón, pellejáme este cosón.

Lozana. Vivas y adivas, siempre coplica ${ }^{10}$.

8. Son los casos, p. ej., del adivas en una incoherente exclamación del pastor Gilanudo dirigida a su interlocutor Parrucho: «jallá adibas, maxmordón!» en la Jornada V de la Comedia llamada Vidriana de Jaime de Huete (Autos, Comedias y Farsas de la Biblioteca Nacional, Madrid, 1964, t. II, p. 72), y del adivas de la misma expresión constante en la Jornada II de la Farsa llamada Salmantina de Bartolomé Palau, editada por Alfred Morel-Fatio, BHi 2, 1900, p. 237-77; ad hoc, p. 267: aquí aparece en un parlamento del pastor Beltrán, que intenta besar a Teresa, moza: «Beltrán. Pardios, que hos he de besar. / Sus, estad quedita, amores. / Teresa. ¡Ay, señora! / Beltrán. ¡Sus, callar, allá adiuas y dolores!», vv. 1032-33.

9. Farsa llamada Salmantina, Jornada IV, vv. 2062-69: BHi 2, 1900, p. 289.

10. Francisco Delicado, La Lozana andaluza, ed. Bruno N. Damiano, Madrid, 1975, mamotreto XXX, p. 240-41. 
En contraste de estos textos, véanse los siguientes alusivos a las carótides del animal. Un despechado Galán en amores, quejándose a viva voz, dice:

$\begin{array}{ll}\text { Galán. } & \text { Desastrado coraçón, } \\ & \text { ¿Por qué me das tanta afrenta? } \\ & \text { ¡Rebienta, triste, rebienta } \\ & \text { y acábese mi pasión! } \\ \text { Pastor. } & \text { (Él deue tener torçón). } \\ \text { Galán. } & \text { ¡O }[\mathrm{h}] \text { mis pasiones esquivas! } \\ \text { Pastor. } & \text { (Dios, que es ranilla o adiuas, } \\ & \text { según llos dolores son!). } \\ & \text { ¿Tú quiés, hermano, sanar? } \\ & \text { As de tragarte aqueste ajo, } \\ & \text { Sacarte á el dolor de quajo } \\ & \text { que no llo dexe parar }{ }^{11} .\end{array}$

Tanto ranilla como adivas, son enfermedades de animales que afectan al tubo digestivo: aquélla, 'retención de sangre en el recto del animal vacuno'; ésta, sin duda, la referida inflamación. De aquí que, con toda propiedad, el humilde Pastor proponga el remedio casero pueblerino de tragarse un ajo para arrancarle el mal físico 'interior' que él supone aqueja al Galán. De nuevo (al igual que en la pieza de Palau) el Pastor, en su reducido vocabulario rústico sobre enfermedades, aplica nombres mórbicos propios de bestias, los únicos familiares para él, a lo que cree padecer el Galán: 'cuágulos e sangre en el recto' y 'esquinancia' de garganta.

En el contexto que sigue, tomado de una obra de Lope de Vega, el parlamento corresponde a dos labriegos (Lisardo y Salvano) y a un caballero (Otón):

$\begin{array}{ll}\text { Otón (a Lisardo). } & \begin{array}{l}\text { ¿Cómo queréis encubrir } \\ \text { sol que por cristal se ve? }\end{array} \\ \text { Lisardo. } & \begin{array}{l}\text { Id, señor, vuestro camino } \\ \text { y dejadnos varear. }\end{array} \\ \text { Otón. } & \begin{array}{l}\text { Pues yo, ¿no sabré ayudar? } \\ \text { ¿Ayudar? ¿Qué desatino! }\end{array} \\ \text { Lisardo. } & \text { Tenéis muy blandas las manos. } \\ \text { Otón. } & \begin{array}{l}\text { ¿Habéislas tocado vos? } \\ \text { Qualvano. }\end{array} \\ & \text { mues venga, plegue a Dios, } \\ & \text { mala pedradas yos don, },\end{array}$

11. Diego Sánchez de Badajoz, Recopilación en metro, ed. Weber de Kurlat, Buenos Aires, 1966, p. 489-90. 


\section{BULLETIN HISPANIQUE}

echenos sendas ayudas

e váis a cenar con dudas,

per secula seculorum. Amén ${ }^{12}$.

Obviamente, el triple conjuro que lanza Salvano al caballero, es que recaigan sobre él, por impertinente con Lisardo, tres enfermedades internas de cuadrúpedos: muermo ('inflamación nasal y de glándulas linfáticas'), tolón/tolano ('infección de encías') y adivas ('esquinancia, anginas'), con lo que, por añadidura, a la sordina se le está llamando 'animal cuadrípedo'. Nótese el cambio de sentido que se le da a ayudar: en las entradas de Otón y Lisardo obviamente es 'asistir a', 'mediación de asistencia' y se aplica la voz a Lisardo en el deseo de asistirle en la faena que lleva entremanos, el varear la mies para sacar su grano; en cambio, Salvano trastornando el sentido de ayuda, refiere el término, con no poca sorna, al interior del cuerpo de Otón, suponiéndole infectado por dichas enfermedades; por ello el ayuda de Salvano lleva la acepción de 'medicamento líquido que se aplica por el ano con una lavativa'. Lo que demuestra bien que al adivas textual le corresponde la significación de afección a garganta.

Pero volvamos a centrarnos ya en el preciso objeto del trabajo: el v. 302c del $L B A$. Ese adivas suyo está muy lejos de ser el sustantivo bifronte acabado de comentar. Por supuesto, ninguna de las dos enfermedades que lleva tal nombre es mortal en los equinos y relativos brutos, y menos aún que llegue a ocasionarles muerte inminente; ambas ciertamente son afecciones sufribles y, desde luego, normalmente pasajeras, en particular, la inflamación de garganta. Tampoco encaja bien con la realidad el que la aparición de la esquinancia en las bestias haya de ser efecto o consecuencia inmediata del comer ciertas hierbas: inferencia de lo que entienden los mencionados editores del $L B A$ al aplicar al pasaje en cuestión la idea de 'haber muerto el caballo por mal de garganta', o sea, lo que el Arcipreste no dice. La frase ruiciana tomáronlo adivas, puesta en el contexto de cualquiera de las dos acepciones del vocablo albeitero, si no incoherente, resulta ser de bien escaso sentido: mal sientan sintácticamente unas anginas (adivas) como sujeto de tomaron, entendido el verbo en su acepción estricta de 'coger': las adivas/ anginas no 'cogen' al bruto, sino el bruto es quien 'coge' adivas/anginas; así lo impone la lógica gramatical; $y$, por otra parte, queda dicho ya que la realidad de lo que es la tal dolencia equina -y a lo que llegan sus efectos- no permite extender la noción verbal de tomar a 'matar', refiriéndolo a la dolencia.

12. Lope F. de Vega. El villano en su rincón. Obras escogidas, ed. Carlos Sainz de Robles, Madrid, 1987, 5a edic., t. I, p. 1196. 
El poeta arcipreste echa mano en el v. 302c del homófono (en plural) de los adivas que venimos comentando, cuya acepción la recoge debidamente Tomás A. Sánchez (1790) en nota ad hoc: «cierto animal del campo, semejante al lobo o al perro que se mantiene de la caza». *Adiva (ar. $\underline{d}^{\prime}$ 'b 'lobo') ${ }^{13} \mathrm{es,} \mathrm{en}$ efecto, una de las tres variedades del chacal o acaso un canino emparentado con la del perro salvaje africano de oreja grande arredondeada, piel pinta marrón con manchas blancas y cola azorrada, que se sustenta de animales muertos $y$, sin duda, también de presas de animales viejos o enfermizos atrapadas por ellos en manada, cual las del lobo; si este canino corrió pot tierras de la Península, debió de haberse extinguido tempranamente. El castellano sólo conoce el plural del sustantivo, adivas, y, frente a otras ocurrencias suyas, en el pasado siempre en uso femenino por influjo de su vocal final, favorecido éste por la fonación de la inicial de la voz. Tal vocablo se deja ver en otros pasajes literarios, con significación paralela a la de la frase en cuestión y en función del mismo propósito intencional que el de Juan Ruiz, por ej., en los dos textos que siguen, tomados del Lucidario, obra supuestamente trabajada en el scriptorium regium de Sancho IV de Castilla, y de un Cancionero de 1516 respectivamente:

...e por eso [el ser la tierra arenosa e seca] non pueden ý [i.e., en una tierra alliende Ynglatierra] veuir los conejos, porque non pueden ý fazer cueuas en que se ascondan en la arena. E eso mismo contesçe de los rraposos que goaresçen en las cuebas, ca en aquella tierra non

13. Alterna con las formas adiblaldibladiveladife, que, como adiva, llevan aglutinado el artículo y oscurecida su $l$ del mismo por inmediatez de la consonante solar $d$, salvo en aldib, alternancia no registrada en los diccionarios lingüísticos. Las primeras docencias del vocablo se encuentran, bajo las formas adib, aldib y adibe, en el Picatrix (ca. 1256) de Alfonso X (Concordances and Texts of the Royal Scriptorium Manuscripts of Alfonse X. Madison, Wi, 1978): «en el XXII grado [del signo de Tauro] sube un adib enfiesto, et qui nasciere en el sera creydo de sus palabras e sesudo e entendudo» fol. 1v, p. 3 (otros dos casos, en fol. 7r, p. 20 y fol. 10r, p. 26); en la descripción del grado XXX del signo de Escorpio tras la «figura de una mugier con una verga doro», sigue "figura de un aldib», fol. 7v, p. 21; «en la Segunda faz [del signo de Leon] sube un ydolo que tiene [...] una çampoña fecha de cuernos de adibe», fol. 10r, p. 26 (lo de cuernos no cae bien con el adiveladibe; pero ha de tenerse en cuenta la terminología simbólica del Picatrix; cabe no obstante -aunque no lo crea- que este adibe apunte a distinto animal y, de ser así, la primera docencia de esta forma sería la que se viene señalando como tal del año 1326, constante en el Libro del caballero y el escudero, de Juan Manuel (Obras completas, ed. José M. Blecua, t. I, Madrid, 1981, p. 88). La forma más prevalente y común desde el s. XIV es, precisamente, la de adiveladibe, concurrente con la de adiva (ésta siempre en plural y poco profusa); la de adife es muy infrecuente, consta, p. ej., en la Crónica de Álvaro de Luna: "Aun las fieras alimañas bravas [...] non usarían tal crueldad como es dar la muerte a quien las sirve e las acompaña e las sigue, asi como fasce el adife» (ed. J. de Mata Carriazo. Madrid, 1940), p. 427. 
ay rraposos, mas ay animalias que semejen [sic] a ellos e de los louos, que llaman adibas; e estas andan en pos los leones e el su gouernio es de la carne que dexan los leones que non quieren comer, e de aquello se mantienen ${ }^{14}$.

$$
\begin{aligned}
& \text { Antón, á plazer de Dios } \\
& \text { con vuestras malicias bivas, } \\
& \text { aunque cisma ay entre nos, } \\
& \text { hazés lo que cumple a vos } \\
& \text { y a mí quem' mate[n] adivas }{ }^{15} \text {. }
\end{aligned}
$$

El contexto del jocoso poema excluye que este adivas signifique 'inflamación de garganta' (como quiere algún crítico): Don Alonso de Aguilar ha obsequiado a Antón de Montoro (1404-ca.1480) con una porción de trigo para él y otra de cebada para su caballo; el mordaz coplero le pide al noble que el obsequio sea todo en trigo, como especie más valiosa; pero con suma gracia, pues la poesía la pone toda ella en boca de su caballo, quien quejándose de la ruindad y desatención de su amo para con él al privarle de la cebada que el noble le quiere dar, le reprocha que desde que lo compró en Sevilla (entonces "redondo como una bola») no ha hecho sino enflaquecer por su avaricia y que si ahora le deja sin el grano prometido y destinado a él por el conde, muerto ya de hambre, se lo van a devorar las adivas: 'haces lo que a ti cumple y a mí ¡que me muera de hambre, que me maten las alimañas!'.

Idéntica idea reflejan los dos textos cervantinos que siguen, uno del Rinconete y Cortadillo, otro del Quijote, el de éste más explícito si cabe, dado el paralelismo de adivas con avispas y cerdos, que él conlleva.

En el primero, la moza Cariharta, entre clamorosos jimoteos por el vareado que le había aplicado el ingrato Repollido, pillejo con quien perdió y gastó su mocedad y la flor de sus años, dice a voces destempladas:

Respetada me vea yo en los infiernos si más lo fuera de aquél, león con las ovejas y cordero con los hombres. ¿Con aquél había yo de comer más pan a manteles ni yacer en uno? Primero me vea yo comida de adivas estas carnes que me ha parado de la manera que ahora veréis...16

14. Richard P. Kinkade, ed., Los «Lucidarios» españoles, Madrid, 1968, cap. XCII, p. 294. La ocurrencia de adivas en este texto ( $c a$. 1293) es primera docencia de tal forma.

15. Cancionero de obras de burlas provocantes a risa, ed. P. Jauralde Pou, Madrid, 1974, p. 110.

16. M. de Cervantes, Rinconete y Cortadillo, en Obras Completas, ed. A. Valbuena, Madrid: Aguilar, 1952, p. 845. Es claro que la moza alude a su muerte, de ahí que este adivas no puede 
En el segundo, Sancho Panza pide la espada a su amo para acuchillar a unos cuantos cerdos de la piara que les acababa de 'desgraciar' a ambos, esto es, de haberlos dejado pringados de su basura; a lo que el bueno de don Quijote responde refiriéndose a los cochinos:

Déjalos estar, amigo; que esta afrenta es pena de mi pecado, y justo castigo del Cielo es que a un caballero andante vencido le coman adivas y le piquen avispas y le hollan cerdos ${ }^{17}$.

Algo dudosa, por imprecisa, es esta otra docencia, al comienzo mismo de una pieza de Lope, en boca de un Juan Labrador, debido a que el reventar del segundo verso es verbo acomodable a las anginas; pero, como asimismo lo es también a canino (reventar a palos a un perro), es justo el pensar que el poeta con el adivas se refiere al carnícero animal, tanto más cuanto que tampoco convienen a la dicha dolencia ni el tostadas ni menos el paradas, $\mathrm{y}$ sí a la alimaña:

¡Malas adiuas tostadas, que las revienten. Amén!

Que no es posible que estén sólo un momento paradas ${ }^{18}$.

En conclusión, hagamos notar que la fábula ruiciana, en lo que concierne al caballo, presenta en su desarrollo seis pasos secuenciales, a saber: $1^{\circ}$, el caballo mata a coces al león; $2^{\circ}$, despavorido por ello, éste huye a aguas vivas (esto es, 'cabriolando y a todo correr ${ }^{19}$ ); $3^{\circ}$, al fin, se detiene y come hierbas esquivas sin mesura; $4^{\circ}$, como efecto de lo cual, perdió sus fuerzas: andaba con dificultad, con gran fatiga, iva mucho cansado; $5^{\circ}$, tomáronlo adivas: es el debilitamiento del animal, su incapacidad de correr ágilmente (o si se quiere su muerte misma, tras haberse envenenado) lo que ocasiona al caballo el ser atrapado por los chacales, y $6^{\circ}$, fue por ellos devorado: viene implicado en el sintagma mismo tomáronlo ('cogido, se lo devoraron'), pero se explicita en la metafórica moral de la fábula, referida también a la muerte del león: assí mueren los locos golosos, 302d. Juan Ruiz, que para resaltar la viveza procesal de la acción ha construido esta estrofa, como tantas otras, con una serie de

significar sino los caninos salvajes 'devoradores de carnes de cadáveres'.

17. Quijote, II, cap. LXVIII.

18. Lope de Vega, El Caballero de Illescas, en Obras, ed. R. Academia Española, segunda serie a cargo de Emilio Cotarelo y Mori, t. IV, Madrid, 1917, p. 109 b.

19. Véase al respecto nuestro estudio "Aguas byuas, LBA 302a». Revista Canadiense de Estudios Hispánicos, 27, 2003, p. 347-54. 
oraciones coordinadas (cuatro), deja al lector que mentalmente establezca él la obvia subordinación de las tres últimas. Es típico recurso del poeta.

La glotonería -repetimos-, cual al león, lleva al caballo a envenenarse y a debilitarse o, incluso, a su muerte, por lo que termina por ser irremediable presa de los carniceros caninos y a ser devorado por ellos.

\begin{abstract}
Abreviaturas
DCE Diccionario Crítico Etimimológico de la Lengua Castellana, 1980-1981.

DHLE Diccionario Histórico de la Lengua Española, 1972.
\end{abstract}

\title{
Obras utilizadas
}

Aguado José María. Glosario sobre Juan Ruiz, poeta castellano del siglo XIV. Madrid, Espasa-Calpe, 1929.

Alfonso X, Picatrix (en Concordances and Texts of the Royal Scriptorium Manuscripts of Alfonse X. ed. Llyot A. Kasten, John Niti y Asociados, Madison, Wi, The Hispanic Seminary of Medieval Studies, 1978.

Blecua Alberto, Libro de buen amor. Barcelona, Planeta, 1983. Nueva edición: Madrid, Cátedra, 1992.

Brey Mariño María, ed. Libro de buen amor, 17a edic. Madrid, Castalia, 1990; $1^{\text {a }}$ edic. Valencia, 1954.

Cejador y Frauja Julio, ed. Libro de buen amor, 11 a reimpr. Madrid, Espasa-Calpe, 1970; $1^{a}$ edic. Madrid, Ediciones La Lectura, 1913.

Cervantes Miguel de, Rinconete y Cortadillo, en Obras Completas, ed. A. Valbuena. Madrid, Aguilar, 1952, p. 833-42.

Corominas Joan, Diccionario Crítico Etimológico de la Lengua Castellana. Madrid, Editorial Gredos, 1976, 3 vols. (reimpr. de la de Berna, 1955-1957; última edición con la colaboración de José A. Pascual: Madrid, Gredos, 1980-1991, 6 vols.).

Covarrubias Sebastián de, Tesoro de la lengua castellana o española, según la impresión de 1611, ed. Martín de Riquer. Barcelona, Horta, 1943.

Chiarini Giorgio, ed. Libro de buen amor. Milán-Nápoles, Riccardo Ricciardi, 1964.

Delicado Francisco, La Lozana andaluza, ed. Bruno N. Damiani. Madrid, Porrúa Turanzas, 1975.

Fontanals, Joaquín R. y Lidia Pons Griera. Libro de buen amor, $7^{\text {a }}$ edic. Barcelona, Bruguera, 1982; $1^{\text {a }}$ edic., 1971.

García Cabero Franciso, Instituciones de Albeytería y examen de practicantes de ella. Madrid, Oficina de Joseph Doblado, 1773. 
Huete Jaime de, Comedia llamada Vidriana. En Autos, Comedias y Farsas de la Biblioteca Nacional, ed. Justo García Morales. Madrid, 1964, t. II, n. XVI. Jauralde Pou, Pablo de, Libro de buen amor. Tarragona, Ediciones Tarraco, 1981.

- y Juan A. Bellón, eds. Cancionero de obras de burlas provocantes a risa. Madrid, Akal, 1974.

Joset Jacques, ed. Libro de buen amor. Madrid, Espasa Calpe, 1974, 2 vols. (Clásicos Castellanos, n. 14 y 17). Nueva edición: Madrid, Altea Alfaguara, Clásicos Taurus, 1990.

Juan Manuel Infante de Castilla, Obras Completas, ed. José Manuel Blecua. Madrid, Editorial Gredos, 1982, 2 vols.

Jurado José, «Aguas byuas, LBA 302a». Revista Canadiense de Estudios Hispánicos, 27, 2003, 347-54.

Kinkade Richard P., ed. Los «Lucidarios» españoles, Madrid, Gredos, 1968.

Mata Carriazo Juan de, ed. Crónica de Don Álvaro de Luna, Condestable de Castilla, Maestre de Santiago.Madrid, Espasa Calpe, 1940.

Menéndez Peláez Jesús, ed. Libro de buen amor. León, Everest, 1985.

Nebrija Antonio de, Vocabulario Español-Latino, ed. Real Academia Española. Madrid, 1951; edición facsimilar del Dictionarium ex hispaniensi in latinum sermonem. Salamanca, ¿1495?.

Palau Bartolomé, Farsa llamada Salmantina, ed. Alfred Morel-Fatio, Bulletin Hispanique, 2, 1900, p. 237-77.

Ramírez Francisco B., Discurso de Albeytería. Nuevo conocimiento de algunas enfermedades hasta aora ignoradas. Madrid, 1629.

Real Academia Espańola, Diccionario de la lengua castellana [Diccionario de Autoridades]. Madrid, Gredos, 1990, 3 vols.; edición facsimilar del original: Madrid, Francisco del Hierro, 1726-1739.

- Diccionario Histórico de la Lengua Española. Madrid, Academia Española, seminario de lexicografía, 1960, t. I: a-alá.

Sachs Georg, ed. El libro de los caballos. Tratado de albetría del siglo XIII. Madrid, Centro de Estudios Históricos, 1936.

Salvador Miguel Nicasio, ed. Libro de buen amor. Madrid, Editorial Magisterio Español, 1972, Novelas y Cuentos, n. 117.

Sánchez de Badajoz Diego, Recopilación en metro, ed. Weber de Kurlat. Buenos Aires, 1966.

Vega Lope F. de, El Caballero de Illescas, en Obras [de Lope de Vega], ed. Real Academia Española, segunda serie a cargo de Emilio Cotarelo y Mori. Madrid, 1917 , t. IV.

- El villano en su rincón. En Obras escogidas [de Lope de Vega], ed. Carlos Sainz

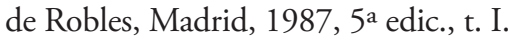

